\title{
Prevalence of Gastrointestinal Helminths in Exotic and Indigenous Goats Slaughtered in Selected Abattoirs in Port Harcourt, South-South, Nigeria
}

\author{
Ovutor Owhoeli, ${ }^{1}$ Kingsley Elele, ${ }^{2}$ and Lebari Barine Gboeloh $^{2}$ \\ ${ }^{1}$ Department of Animal and Environmental Biology, University of Port Harcourt, P.M.B 5323, Choba, Port Harcourt, \\ Rivers State 500001, Nigeria \\ ${ }^{2}$ Department of Biology, Ignatius Ajuru University of Education, P.M.B 5047, Port Harcourt, Rivers State 500001, Nigeria
}

Correspondence should be addressed to Ovutor Owhoeli; ovuforever@yahoo.com

Received 29 November 2013; Accepted 24 December 2013; Published 13 February 2014

Academic Editors: P. Durrens and Q. Yu

Copyright (C) 2014 Ovutor Owhoeli et al. This is an open access article distributed under the Creative Commons Attribution License, which permits unrestricted use, distribution, and reproduction in any medium, provided the original work is properly cited.

\begin{abstract}
A total of 213 faecal samples were collected from four abattoirs and households to determine the prevalence of helminthes infections in exotic and indigenous goats in Port Harcourt, South-South, Nigeria. The study revealed that out of 153 exotic goats (Red Sokoto) Capra hircus, 112 were infected with various species of gastrointestinal helminths; out of 60 indigenous goats (West African dwarf) Capra hircus, 49 were also infected with various types of gastrointestinal helminths. The formol-ether concentration method was used to analyse the specimens. The study revealed that an overall prevalence of (75.5\%) was recorded, out of which 57 (76.0\%), 55 (70.5\%), and 49 (81.6\%) were recorded for exotic goat in the months of May-September, 2010, exotic goat in the months October 2010-February, 2011 and for indigenous goats, respectively. The overall prevalence amongst the infected animals was not statistically significant $(P>0.05)$. Species of helminthes revealed from the study were, Haemonchus, Strongyloides, Chabertia, Trichuris, Ostertagia, Bunostomum, Trichostrongyloida, Ascaris, Tenia, Avitelina, Fasciola, Eurytrema, Gastrothylax, Schistosoma, and Dicrocoelium.
\end{abstract}

\section{Introduction}

Ruminants, cattle, goats and sheep, represent an important source of animal protein in many countries of the world, supplying a good percentage of the daily meat and dairy products in cities and villages in such countries including Nigeria [1]. Apart from being the source of animal protein, their wastes are also very important in agriculture $[1,2]$. These animals are used in special ceremonies such as wedding and burials in most parts of Nigeria. However, parasitic diseases coupled with inadequate management hampered the productive husbandry of these animals $[2,3]$.

Gastrointestinal parasitic infections are world-wide problem for both small and large-scale farmers, but their impact is greater in Sub-Saharan Africa due to the availability of a wide range of agroecological factors suitable for diversified hosts and parasite species [3]. Gastrointestinal parasites are known to be widespread in Nigeria $[4,5]$ and limit ruminant production in many areas of the country $[5,6]$. The direct losses caused by these parasites are attributed to hyper-acuteness and death, premature slaughter, and rejection of some parts at meat inspection, whilst indirect losses include the reduction in productive potential such as decreased growth rate, weight loss, diarrhea, anorexia, and sometimes anaemia [7-9].

Helminths or worms cause a wide range of health problems to both man and animals [10]. Helminthiasis, in large part, is caused by members of the phyla Nematoda and Platyhelminthes [11]. Species belonging to both phyla occupy numerous niches within their mammalian hosts, ranging from intestinal lumen to intravascular and even intracellular sites [12]. They are responsible for substantial loss of productivity in the livestock industry. Their harmful effects on these animals range from gastroenteritis, anorexia, abdominal distention, diarrhoea, emaciation, and so forth; all of which result in serious economic losses to the farmer and the nation in general [13]. Similarly, they constitute a major impediment to efficient and profitable livestock production [14]. 


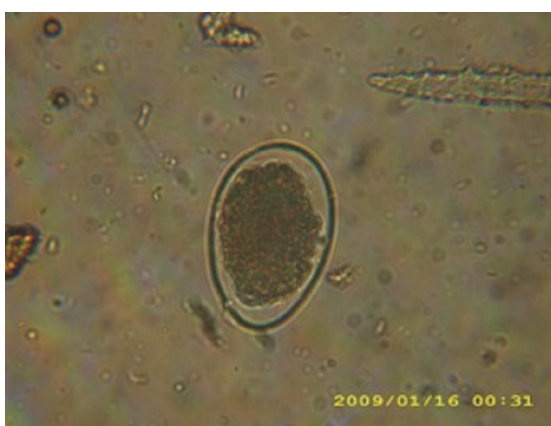

Ostertagia species

(a)

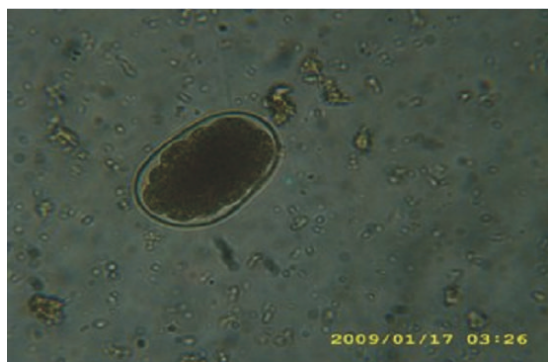

Chabertia species

(d)

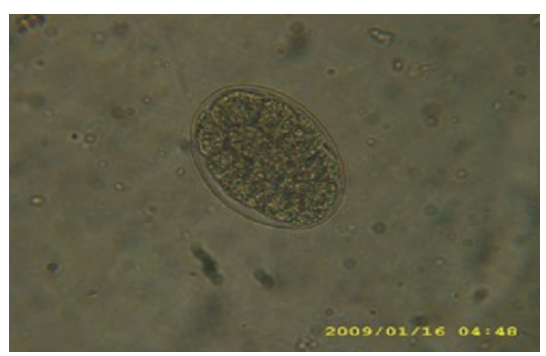

Bunostomum species

(g)

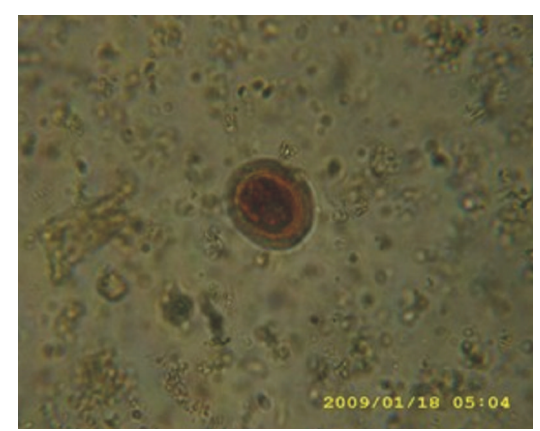

Ascaris species

(b)

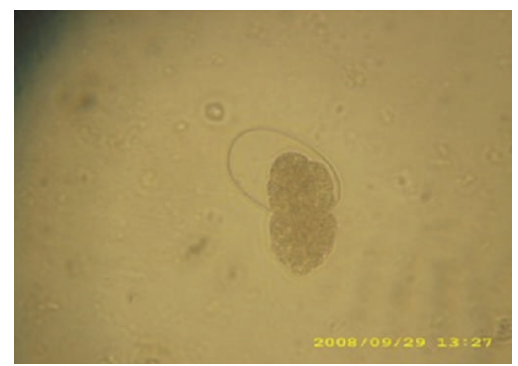

Hatching egg of Chabertia species

(e)

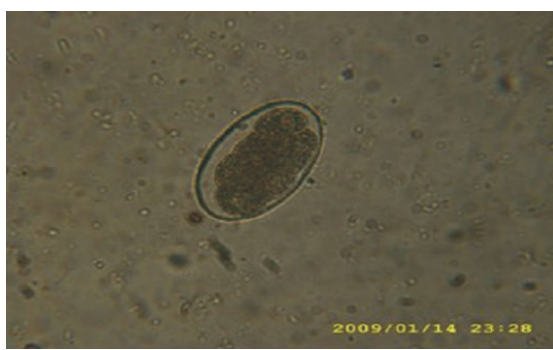

Trichostrongylus spp.

(h)

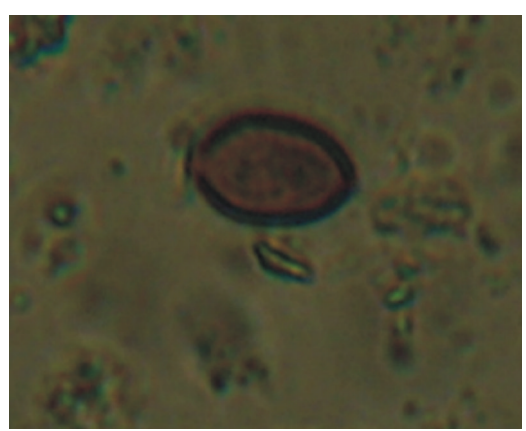

Trichuris species

(c)

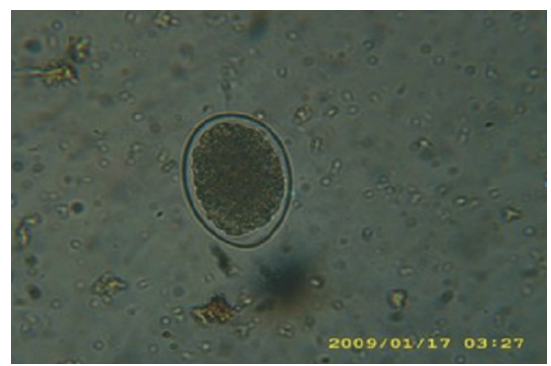

Haemonchus species

(f)

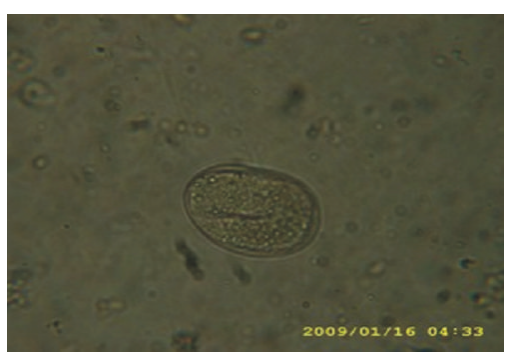

Strongyloides species

(i)

FIgURE 1: Eggs of Nematodes as seen under the $\times 40$ objective of the microscope on slides stained with Lugol's iodine.

The prevalence of gastrointestinal helminths is related to the agroclimatic conditions like quantity and quality of pasture, temperature, humidity, and grazing behavior of the host [15]. However specific parasites may be distributed throughout the world; they have different impact according to production system, management, and geoclimatic conditions [11].

The information on the prevalence and distribution of various species of gastrointestinal parasites of cattle and goats kept by the nomadic Fulani's in Nigeria and those in Port Harcourt are important in the formulation of control strategies for the nomads and other farmers.

\section{Materials and Methods}

2.1. Study Area. The study was conducted in Port Harcourt City, South-South, Nigeria. Obio/Akpor and Port Harcourt city Local governments are commonly referred to as Port
Harcourt city. It is situated on the bonny River within the Niger Delta, South-South, Nigeria. The study area lies between latitude $4^{0} 40^{1}$ and $7^{0} 10^{1}$ to longitude $7^{0} 55^{1}$ east of the Greenwich meridian. It is situated some $60 \mathrm{~km}$ from the open sea, which is immediately where the coastal marshes give way to the land of the interior. Four abattoirs were selected from Rumuodumaya: Ogbogoro, Eliozu, and Aluu communities in the study.

2.2. Collection of Faecal Samples. Faecal specimens were collected from goats in the four aforementioned community abattoirs and individual homes in the study area. Animals were usually slaughtered early in the morning between the hours of 6.30 am and 8.00 am daily for a period of ten months (May, 2008 to February, 2009). Faecal samples were randomly collected weekly from the intestines of slaughtered animals (exotic and indigenous). The samples were collected in clean 


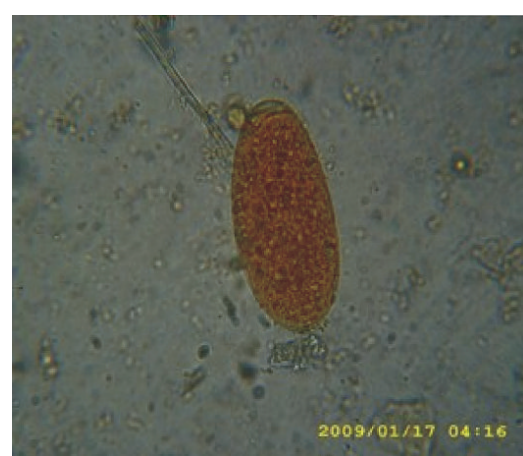

Fasciola species

(a)

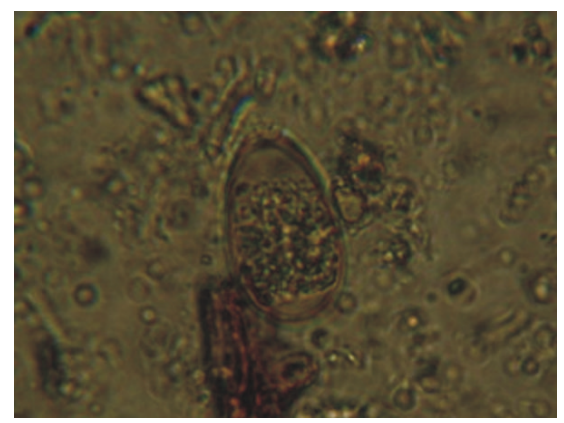

Gastrothylax species

(d)

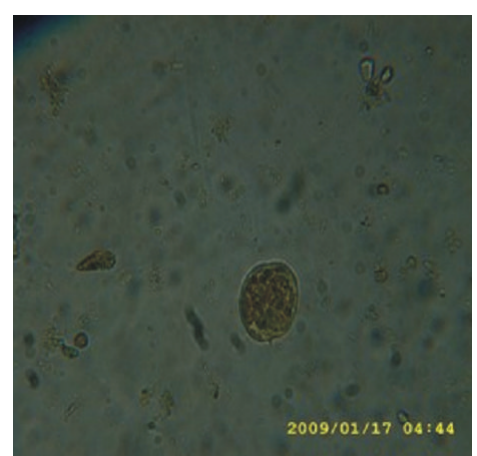

Eurytrema species

(b)

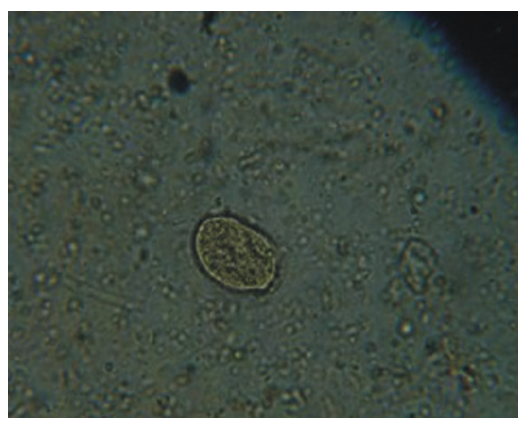

Schistosoma japonicum

(e)

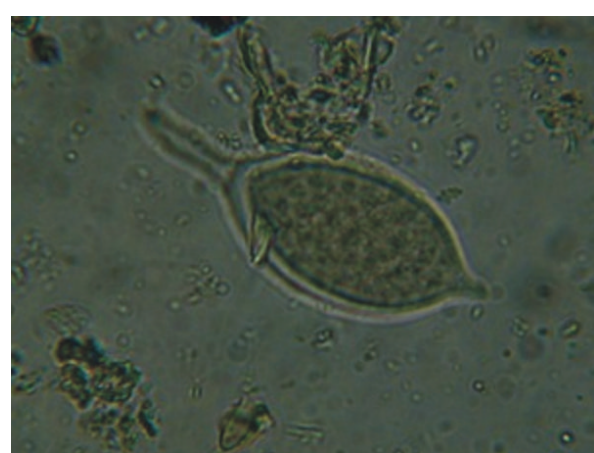

Schistosoma bovis

(c)

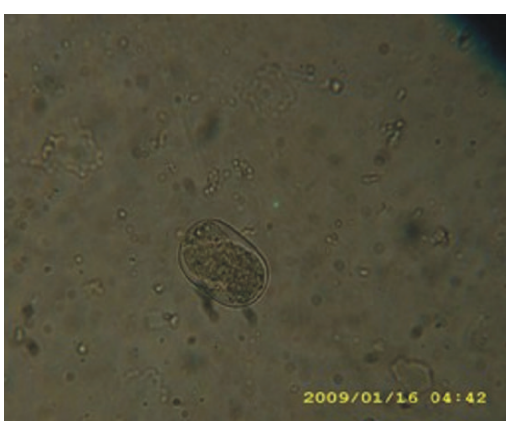

Dicrocoelium species

(f)

FIGURE 2: Eggs of Trematodes as seen under the $\times 40$ objective of the microscope on slides stained with Lugol's iodine.

labeled sterile vials, preserved in $10 \%$ formalin, and taken to the laboratory for microscopic examination.

\subsection{Laboratory Examination. The formol-ether concentra-} tion technique [16] was used to analyze the samples. $1 \mathrm{~g}$ of stool sample was emulsified with $4 \mathrm{~mL}$ of $10 \%$ formol saline in a test tube. The mixture was filtered into a test tube using a cloth gauge and 3-4 mL of diethyl ether was added and it shaken vigorously and allowed to stand for two minutes. The mixture was then centrifuged at 1000 revolutions per minutes (1000 rpm) for 3 minutes. Using a glass rod, the faecal debris from the side of the tube was loosened and the tube was inverted to pour off the supernatants. The tube was returned to its original upright position and the fluid from the side of the tube allowed draining to the bottom. The deposit was mixed by tapping the tube with the finger and using a Pasteur pipette. A drop of the sediment was applied on a microscope slide, covered with a cover slip, and examined under the microscope using $\times 10$ and $\times 40$ objectives. Lugol's iodine was also used as a stain (Figures 1, 2, and 3).

\section{Results}

A total of 75 exotic goats were examined between the months of May and September 2010. Fifty-seven (57) were infected with various species of gastrointestinal helminths as follows (see Table 1).
A total of 78 exotic goats were examined between the months of October 2010 and February 2011. Fifty-five (55) were infected with various species of gastrointestinal helminths as follows (see Table 2).

A total of 60 indigenous goats were examined in four communities during the period of study. Forty-nine (49) were infected with various species gastrointestinal helminthes as follows (see Table 3).

\section{Discussion and Conclusion}

The result of the study clearly indicates a high prevalence rate of gastrointestinal helminthes in cattle slaughtered in four selected abattoirs in Port Harcourt, namely, Eliozu, Ogbogoro, Rumuokoro, and Aluu abattoirs and various homes of indigenous people within the area.

The study revealed that $73.2 \%$ of the sampled exotic goats and $81.6 \%$ of indigenous goats were infected with various species of helminthes parasites. The goat slaughtered between May and September, 2009 had a prevalence rate of $76.0 \%$, October 2009 and February, 2010 had a prevalence rate of $70.5 \%$, while indigenous goat had $81.6 \%$ prevalence rate (see Tables 1 and 2, resp.). These results are consistent with findings of different researchers in the semiarid zone of North-Eastern and South-Eastern Nigeria [17-19].

The helminthes community isolated consisted of sixteen parasitic species, eight (8) nematodes (Haemonchus, Strongyloides, Chabertia, Trichuris, Ostertagia, Bunostomum, 


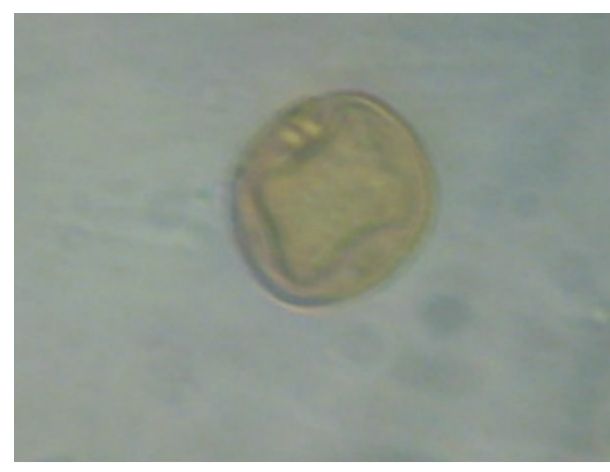

Moniezia benedeni

(a)

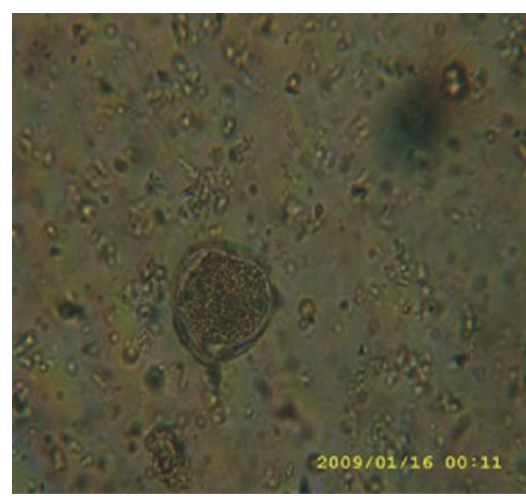

Moniezia expansa

(c)

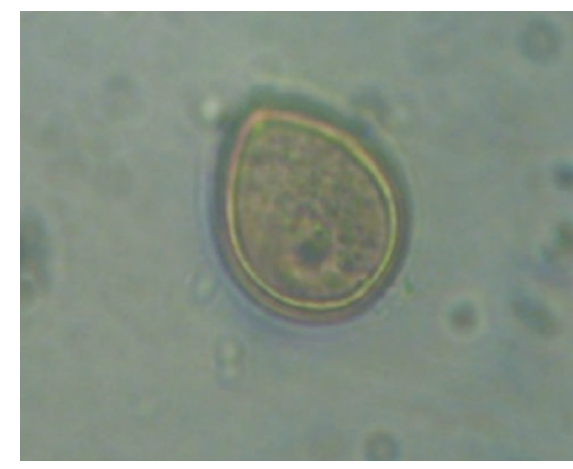

Avitellina species

(b)

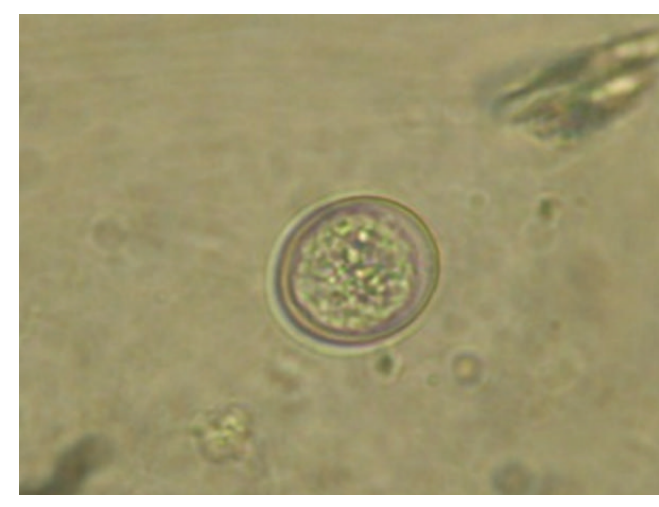

Tenia species

(d)

FIGURE 3: Eggs of Cestodes as seen under the $\times 40$ objective of the microscope on slides stained with Lugol's iodine.

Trichostrongylus, and Ascaris), three (3) Cestodes (Taenia, Moniezia, and Avitellinium), and five (5) (Dicrocoelium, Fasciola, Eurytrema, Gastrothylax, and Schistosoma). Haemonchus species have the highest prevalence in all the positive samples. Fakae (1990) studies the epidemiology of helminthosis in ruminants under the traditional husbandry system in eastern Nigeria and reported prevalence of Haemonchus species as (87.1), higher than other helminthes species. It has been suggested that Haemonchus species can acquire resistance faster than any other gastrointestinal nematodes, like Trichostrongylus, because of its high biotic potential [20]. The area of study shows how vulnerable workers in the abbatoir and people who consume the intestinal parts of the animals may be to infections especially to Taenia and Fasciola which are zoonotic and were observed in course of study. Globally, parasitic and other endemic diseases continue to be a major constraint on profitable livestock production. They are rarely associated with high mortality and easily identifiable clinical signs and their effects are usually characterized by lower outputs of animal products, by products, manure, and traction, all contributing to production and productivity losses.

\section{Conclusion}

In conclusion, various gastrointestinal parasites have been found in cattle in the study area. Hence, the high prevalence rate of helminthiasis in livestock needs to be checked periodically. Regular control measures should be practiced and farmers educated in the proper use of antihelminthiasis. Epidemiological facts suggest that high standard of sanitation in modern animal husbandry will prevent exposure of livestock to graze in deteriorated and environmentally polluted range lands will be effective in controlling disease.

\section{Recommendation}

The following recommendations will help in the prevention or reduction of helminth infections in the study area.

(i) There should be legislative control over slaughtering of goats and their distribution; the abbatoir workers should be properly trained on meat handling and zoonotic infections.

(ii) Animals should be restricted to special areas of land provided by the government for grazing.

(iii) The public should be enlightened on proper cooking of animal parts especially the intestine.

(iv) A comprehensive approach should be adopted to ensure all inclusive meat inspection in the abattoirs before distribution to the public for consumption. 


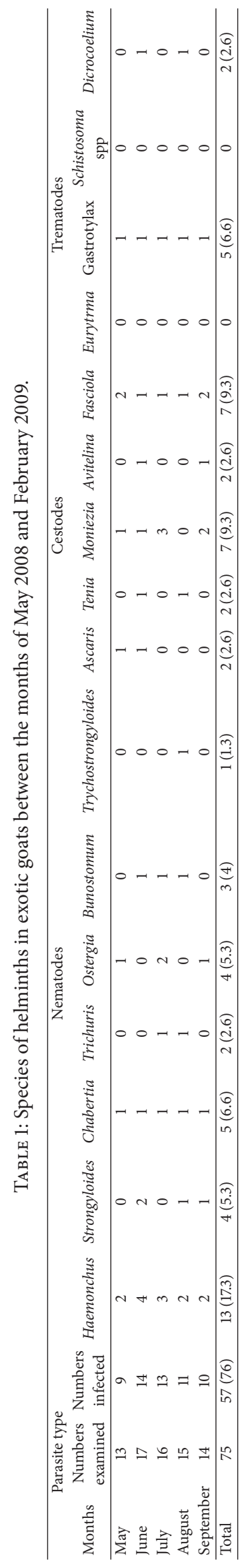




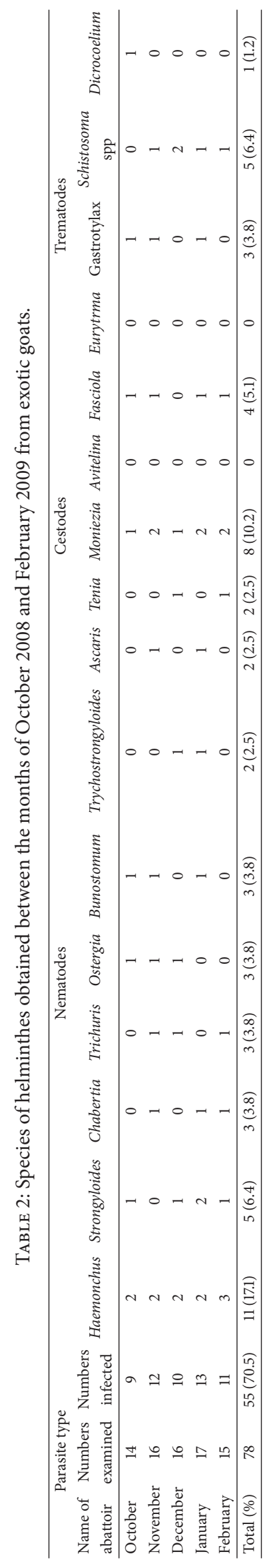




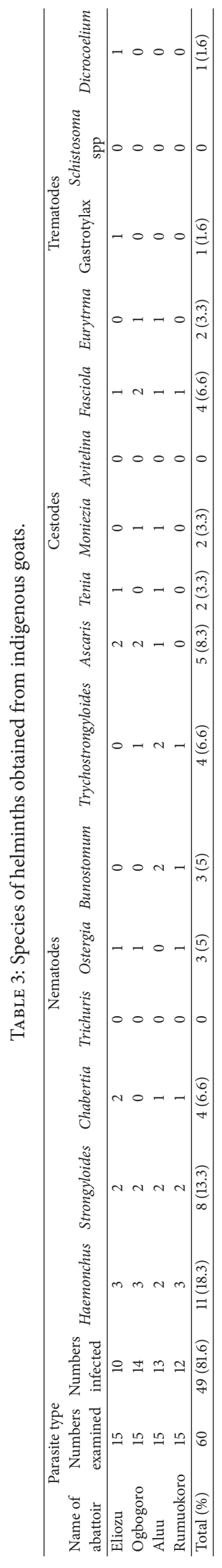




\section{Conflict of Interests}

The authors declare that there is no conflict of interests regarding the publication of this paper.

\section{References}

[1] C. O. Nwosu, P. P. Madu, and W. S. Richards, "Prevalence and seasonal changes in the population of gastrointestinal nematodes of small ruminants in the semi-arid zone of northeastern Nigeria," Veterinary Parasitology, vol. 144, no. 1-2, pp. 118-124, 2007.

[2] D. R. Nawathe, A. S. Sohael, and I. Umo, "Health management of a dairy herd on the Jos Plateau (Nigeria)," Bulletin of Animal Health and Production in Africa, vol. 33, pp. 199-205, 1985.

[3] R. Fikru, S. Teshale, D. Reta, and K. Yosef, "Epidemiology of gastrointestinal parasites of ruminants in western Oromia, Ethiopia," International Journal of Applied Research in Veterinary Medicine, vol. 4, pp. 51-57, 2006.

[4] J. P. Fabiyi, "Seasonal fluctuations of nematode infestations in goats in the savanna belt of Nigeria Bull," Epizootic disease, vol. 21, pp. 227-286, 1973.

[5] M. Eysker and R. A. Ogunsusi, "Observations on epidemiological and clinical aspects of gastrointestinal helminthiasis of sheep in northern Nigeria during the rainy season," Research in Veterinary Science, vol. 28, no. 1, pp. 58-62, 1980.

[6] S. N. Chiejina, "The current status and priorities of research on the epidemiology and control helminth infections of ruminants in West Africa," in Proceedings of the 6th Symposium on Tropical Animal Health and Production, Helminth diseases of ruminants: diagnosis, epidemiology and control, 1995.

[7] E. J. L. Soulsby, Helminths, Arthropods and Protozoa of Domestic Animals, The English Language Book Society and Bailliere Tindall, London, UK, 7th edition, 1986.

[8] J. Nahed-Toral, Q. López-Tirado, G. Mendoza-Martínez, A. Aluja-Schunemann, and F. J. Trigo-Tavera, "Epidemiology of parasitosis in the Tzotzil sheep production system," Small Ruminant Research, vol. 49, no. 2, pp. 199-206, 2003.

[9] R. Gonzalez and A. C. Gonzalez, Alternatives For the Control of Gastrointestinal Nematodes in Sheep, Conf. EEPF Matanzas, Cuba, 2004.

[10] D. G. Colley, P. T. LoVerde, and L. Savioli, "Infectious disease: medical helminthology in the 21st century," Science, vol. 293, no. 5534, pp. 1437-1438, 2001.

[11] M. W. Kennedy and W. Harnett, Eds., Parasitic Nematodes, CAB International, 2001.

[12] D. T. J. Littlewood and R. A. Bray, Interrelationship of the Platyhelminthes, vol. 60, Taylor \& Francis, London, UK, 2001.

[13] A. U. Junaidu and S. G. Adamu, "Survey of Gastrointestinal helminth parasites of dogs of public health importance in Sokoto Metropolis," in Proceedings of the 22nd Annlual Conference of the Nigerian society for Animal Production, Abubaka Tafawa Balewa University Press, March 1997.

[14] O. O. Akerejola, T. W. S. Van Veen, and C. O. Njoku, "Ovine and caprine diseases in Nigeria a review of economic losses," Bulletin of Animal Health and Production in Africa, vol. 27, no. 1, pp. 65-70, 1999.

[15] R. A. Pal and M. Qayyum, "Prevalence of gastrointestinal nematodes of sheep and goats in upper Punjab," Pakistan Veterinary Journal, vol. 13, pp. 138-141, 1993.
[16] K. Agyemang, R. H. Dwinger, D. A. Little, and G. J. Rowlands, Village N'Dama Cattle Production in West Africa: Six Years of Research in the Gambia, International Livestock Research Institute, Nairobi, Kenya, 1997.

[17] B. M. Anene, E. O. Onyekwodiri, A. B. Chime, and S. M. Anika, "Gastrointestinal parasites in sheep and goats of southeastern Nigeria," Small Ruminant Research, vol. 13, no. 2, pp. 187-192, 1994.

[18] B. M. Anene, E. O. Onyekwodiri, A. B. Chime, and S. M. Anika, "A survey of gastrointestinal parasites in cattle of southeastern Nigeria," Preventive Veterinary Medicine, vol. 20, no. 4, pp. 297306, 1994.

[19] B. B. Fakae, "The epidemiology of helminthosis in small ruminants under the traditional husbandry system in eastern Nigeria," Veterinary Research Communications, vol. 14, no. 5, pp. 381-391, 1990.

[20] B. B. Fakae and S. N. Chiejina, "The prevalence of concurrent trypanosome and gastrointestinal nematode infections in West African Dwarf sheep and goats in Nsukka area of eastern Nigeria," Veterinary Parasitology, vol. 49, no. 2-4, pp. 313-318, 1993. 

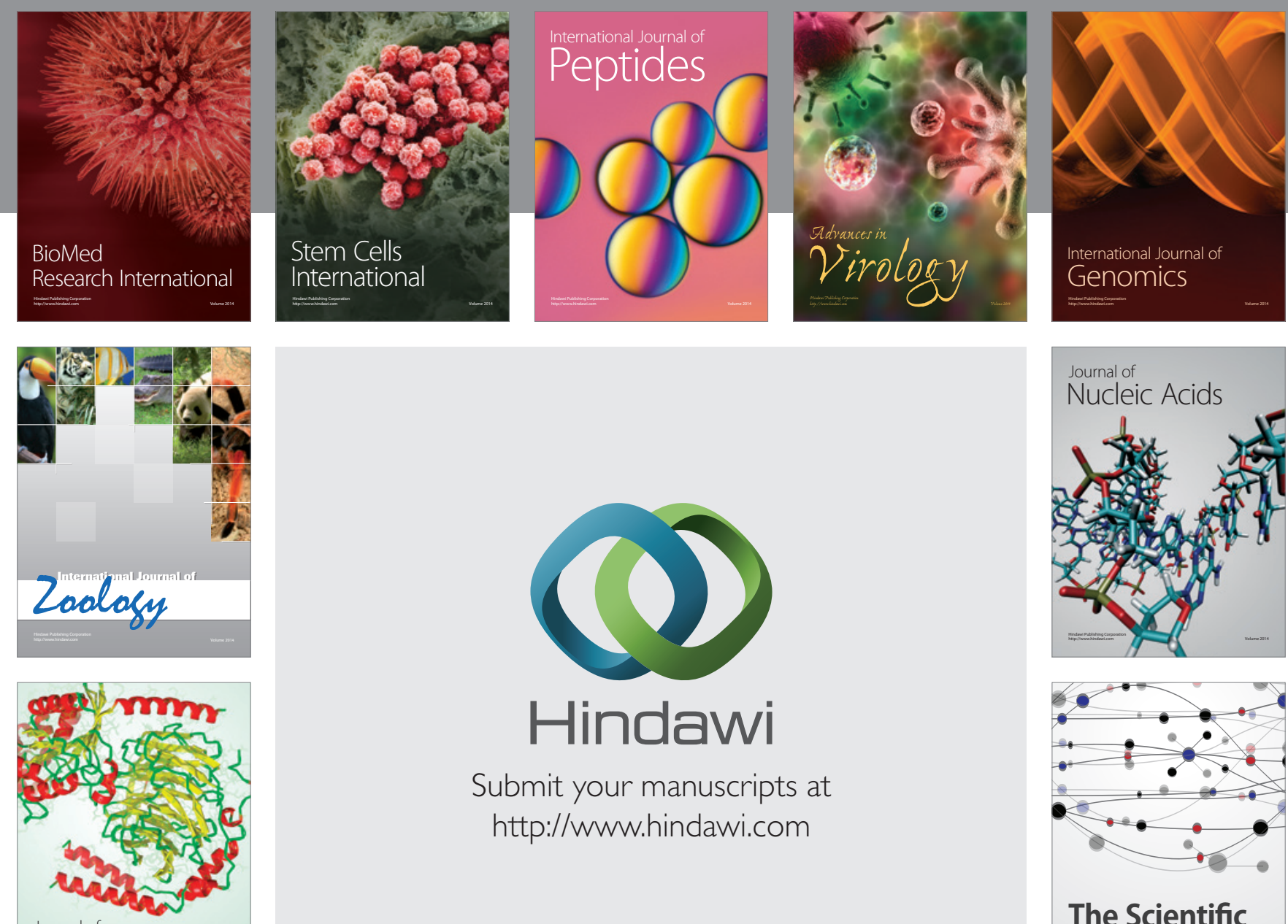

Submit your manuscripts at

http://www.hindawi.com

Journal of
Signal Transduction
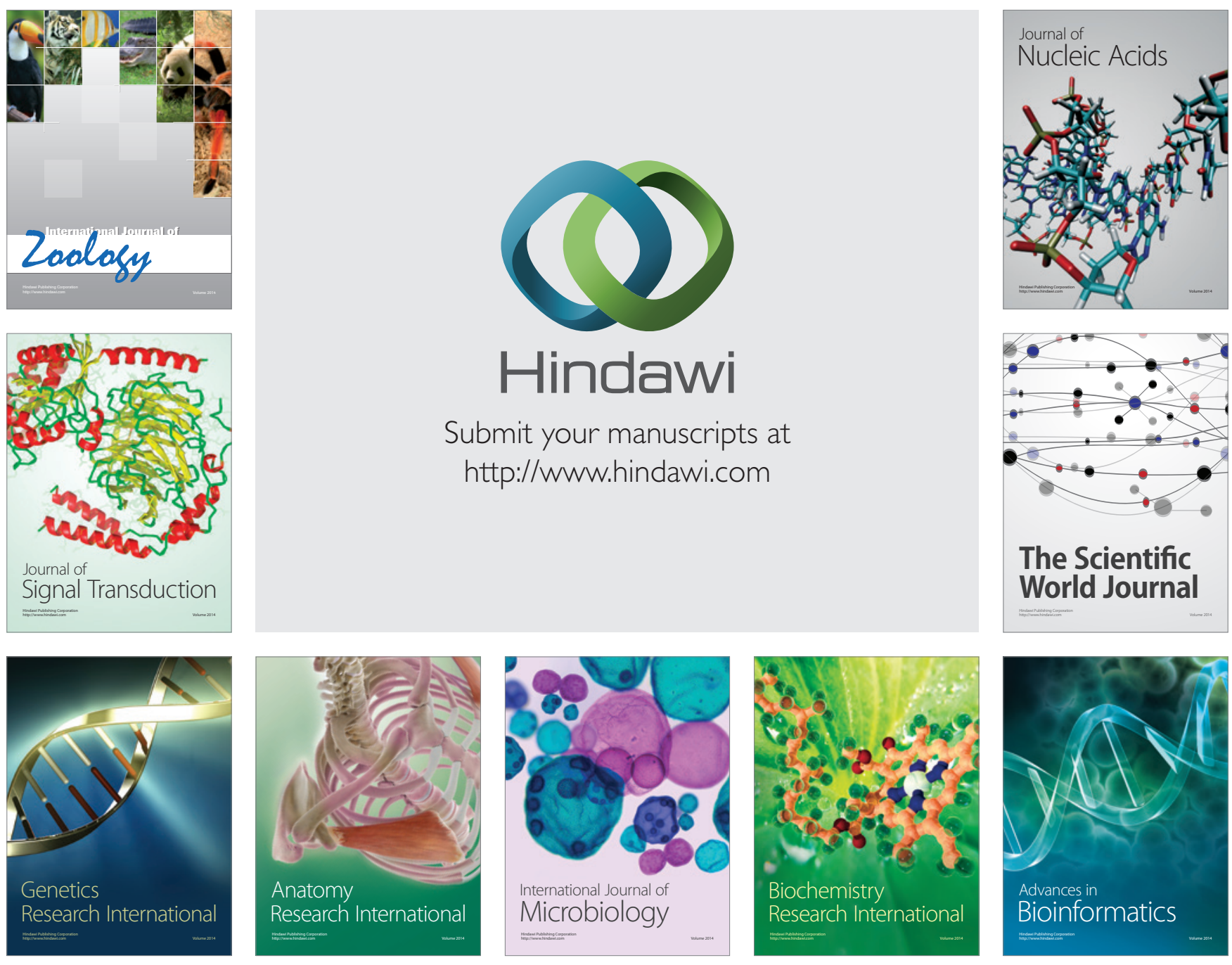

The Scientific World Journal
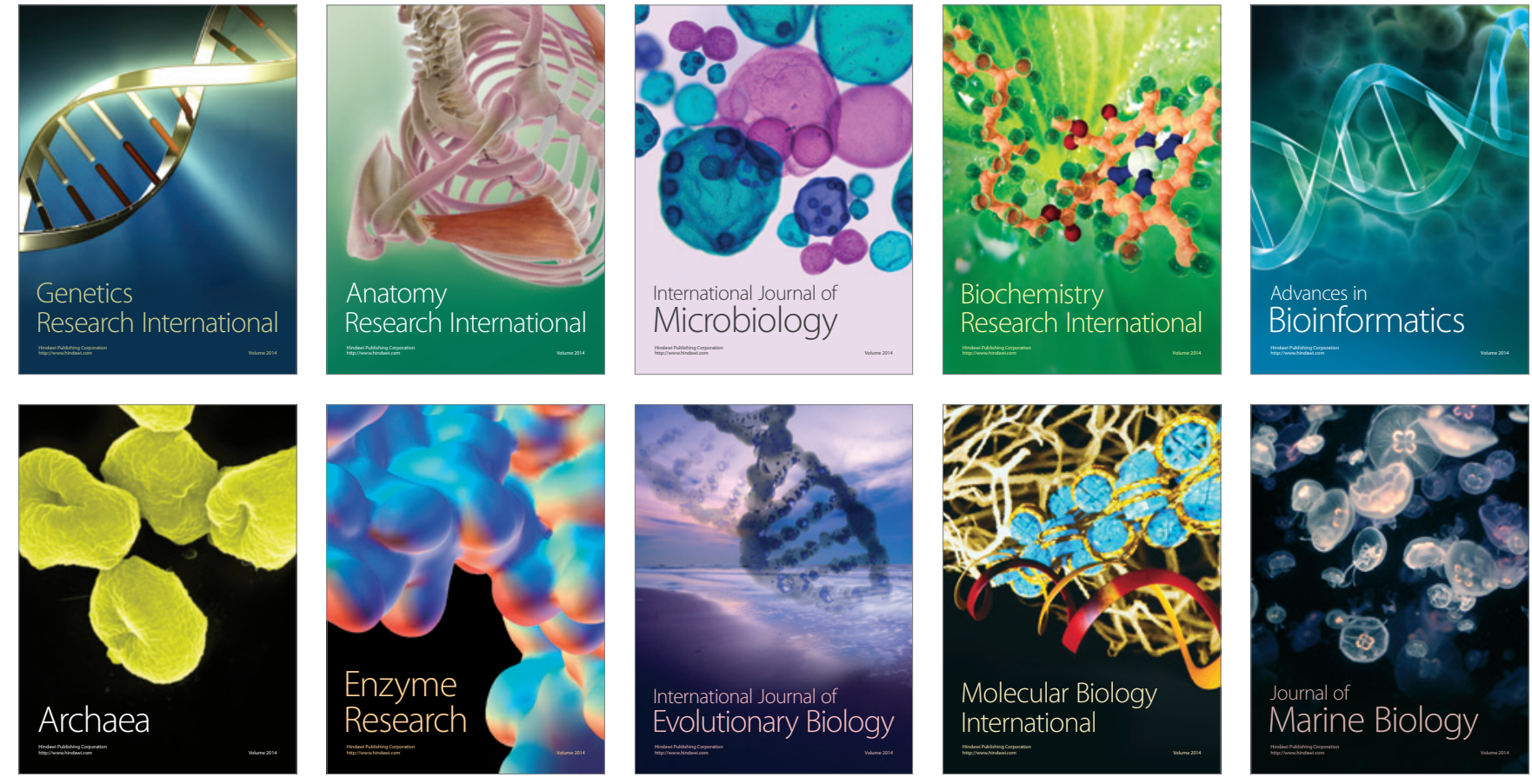